\title{
Staphylococcus caprae
}

National Cancer Institute

\section{Source}

National Cancer Institute. Staphylococcus caprae. NCI Thesaurus. Code C86753.

A species of facultatively anaerobic, Gram positive, cocci shaped bacteria in the phylum Firmicutes. This species is positive for catalase, urease, and phosphatase, and negative for coagulase and oxidase. It can ferment trehalose, mannose, glycerol, galactose, glucose and lactose but not arabinose, cellobiose, fructose, mannitol, ribose, sucrose, turanose, xylitol or xylose. S. caprae has been isolated from goat milk, is part of the human skin flora and can be a human pathogen causing infections of the bloodstream, urinary tract, bones and joints. 